\section{Clostridium difficile: Current Status and Treatment Perspectives}

\section{Abstract}

Clostridium difficile is considered one of the most important pathogens in both, hospital and community settings. This pathogen is responsible for most antibioticassociated colitis in hospitals and a major cause of morbidity and mortality within the elderly. Clostridium difficile infection (CDI) usually appears as a result of antibiotic therapy, which disrupts the normal gut flora. Clostridium difficile infection presents itself in two very distinct ways, it can be either asymptomatic, with the infected person acting as a carrier, or symptomatic, where patients may experience a broad range of symptoms depending on their severity. Symptoms range from mild diarrhea to severe complications such as pseudomembranous colitis, toxic megacolon, bowel perforation, sepsis and death.

Conventional treatment of $\mathrm{CDI}$ consists on antibiotic treatment with vancomycin or metronidazole. However, the number of recurrences after using these treatments is growing exponentially. New molecules such as fidamoxicin have been included in treatment guidelines but still; the cases of recurrent CDI continue to grow. As a result, a novel therapy has emerged: fecal microbiota transplants (FMT). It is a procedure in which fecal matter, or stool, is collected from a tested donor, mixed with a saline or other solution, strained, and placed in a patient by colonoscopy, endoscopy, sigmoidscopy or enema. With its efficacy being proven constantly study after study, it is only a matter of time for health organizations worldwide to include it in the guidelines for rCDI treatment.

Keywords: Clostridium difficile; CDI; RCDI; Fecal transplant; FMT

\section{Beatriz Suay García and María Teresa Pérez-Gracia}

Área de Microbiología, Departamento de Farmacia, Instituto de Ciencias Biomédicas, Facultad de Ciencias de la Salud,

Universidad CEU Cardenal Herrera, Avenida Seminario s/n 46113, Moncada, Valencia, España.

\section{Corresponding author:}

María Teresa Pérez-Gracia

” teresa@uchceu.es

Área de Microbiología, Departamento de Farmacia, Instituto de Ciencias Biomédicas, Facultad de Ciencias de la Salud, Universidad CEU Cardenal Herrera, Avenida Seminario s/n 46113, Moncada, Valencia, España

Citation: Garcia BS, Garcia MTP. Clostridium difficile: Current Status and Treatment Perspectives. J Infec Dis Treat. 2015, 2:1.

\section{Introduction}

Clostridium difficile is considered one of the most important pathogens in both, hospital and community settings. This pathogen is responsible for most antibiotic-associated colitis in hospitals and a major cause of morbidity and mortality within the elderly. $C$. difficile infection (CDI) is increasing at such a rate that the Centers for Disease Control and Prevention (CDC) have assigned it as an urgent threat due its association with antibiotic use and high morbidity and mortality [1]. In 2010, CDI incidence was estimated at 500,000 cases [2], with treatment costs being around 1 billion dollars in the US alone [3].

CDI usually appears as a result of antibiotic therapy, which, by disrupting the normal gut flora, causes dysbiosis (a change of the normal gut bacterial population), thereby enabling colonization of the intestinal tract by $C$. difficile [4].Symptoms rangefrom mild diarrhea to severe complications such as pseudomembranous colitis, toxic megacolon, bowel perforation, sepsis and death [5]. Clostridium difficile has the ability to form spores, which introduces further challenges to reduce transmission seeing as these spores can persist in the environment for long periods and require chlorine or peroxide based sporicidal agents or ultraviolet devices for environmental decontamination [6]. It is this characteristic which makes $C$. difficile distinct from other infectious agents common to the healthcare settings. The most common transmission routes for $\mathrm{CDI}$ are fecal-oral route and direct contact with contaminated surfaces [7]. Person-to-person transmission, environmental contamination and carriage of $C$. difficile on the hands of healthcare workers have been extensively described [8] but it is the admission of asymptomatic CDI patients 
what plays an important role in sustaining $C$. difficile transmission within a ward [9] seeing as their lack of symptoms may result in less strict controls and, therefore, a wider spread of spores within emergency rooms and hospitals in general. CDI treatment is based on antibiotics such as vancomycin and metronidazole [10]. However, about $20 \%$ of patients suffer recurrent cases of CDI after the initial treatment and $40-50 \%$ after treatment for a second episode [11]. Seeing as conventional treatments fail in up to $50 \%$ of the cases, newer treatments such as the fecal microbiota transplantation (FMT) are being used experimentally with positive results [12]. The main purpose of this article is to review the current status of $\mathrm{CDI}$ and the latest findings regarding its treatment options.

\section{Clinical presentations}

Clostridium difficile infection presents itself in two very distinct ways, it can be either asymptomatic, with the infected person acting as a carrier, or symptomatic, where patients may experience a broad range of symptoms depending on their severity. Asymptomatic $\mathrm{CDI}$ is the condition where $C$. difficile is detected in the absence of symptoms of infection. It is thought that these patients are protected from progression of the infection because they can mount a humoral immune response to the clostridial toxins [13]. It is precisely their lack of symptoms what makes them the perfect infection reservoir seeing as they could be spreading toxins without knowing, which would present a risk for other patients and hospital workers [14].

On the other hand, symptomatic CDI has been defined as the presence of diarrheal symptoms along with a stool result positive for $C$. difficile toxins, detection of toxigenic $C$. difficile, or colonoscopic findings demonstrating pseudomembranous colitis [15]. The issue for symptomatic CDI is not the development of clinical manifestations, but the possible appearance of recurrences after receiving the first antibiotic treatment. A study by [16] shows that, out of 1527 patients, $25 \%$ developed a first recurrent $\mathrm{CDI}$ ( $\mathrm{rCDI}$ ) and $9 \%$ went on to suffer two or more rCDIs [16]. Recurrent CDI can turn into a chronic, recalcitrant disease, which can continue for years, leading to a persistent use of antibiotics, repeated hospitalizations, and, in some cases, death [17].

\section{Treatment options}

As CDI infection becomes increasingly common, the number of patients who experience failed treatments or recurrences is also growing. Conventional CDI treatment consists in a 10-14 day course of antibiotics such as metronidazole and vancomycin. However, studies suggest that metronidazole is losing efficacy, which leaves vancomycin as the first-line antimicrobial therapy [18]. This lead to further research with antimicrobials, which resulted in the approval of fidaxomicin by the US Food and Drug Administration (FDA), the first macrolide antibiotic to be approved in more than 20 years for the treatment of CDI. Early studies showed that recurrence rates of CDI were lower with fidaxomicin than vancomycin [19].

The issue with antibiotic treatment is that it represents a doubleedged sword seeing as antibiotics suppress pathogen as well as protective microbiota, causing adverse effects on the intestinal flora. Vancomycin, being a broad-spectrum antimicrobial agent with activity against most Gram-positive organisms, may ultimately increase susceptibility to $\mathrm{rCDI}$ by maintaining a persistently altered state of bowel flora. These cases, where antibiotic treatment is responsible for multiple $\mathrm{rCDI}$, are what have encouraged the development of alternative treatments; with the fecal microbiota transplant (FMT) being the most successful up to now. Early research studies suggested the idea of using probiotics as adjuvants when antibiotic treatment leads to rCDI. In fact, a study by [20] showed that using Saccharomyces boulardii as an adjunct to antibiotics decreased the frequency of relapses in those with $\mathrm{rCDI}$ when compared to a placebo group (34.6\% vs. $64.7 \%$ placebo) [20]. This idea triggered more interest in the development on probiotic-based treatments, which ultimately lead to FMT. The rationale behind FMT is simple, by reintroducing normal flora via donor feces, the imbalance in colonic flora, which has been disrupted by antibiotics, is restored, and therefore reestablishing normal bowel functions. It is a procedure in which fecal matter, or stool, is collected from a tested donor, mixed with a saline or other solution, strained, and placed in a patient by colonoscopy, endoscopy, sigmoidscopy or enema [21]. Another administration option currently under study is the use of encapsulated frozen stool samples [22].

The first FMT dates back to 1958, where fecal enemas were administered to four patients with pseudomembranous enterocolitis, three of which were in critical state, and in all patients symptoms resolved within hours [23]. It was not until 1983 when FMT was used for the first time to treat a confirmed case of CDI [24]. The 65-year-old woman had a "prompt and complete normalization of bowel functions" after receiving the treatment. The year 2013 marked the beginning of controlled trials in which FMT was used to treat $\mathrm{rCDI}$. The first randomized controlled trial proved the efficacy of FMT with a nasoduodenal administration in rCDI patients [25].

Since that first study, approximately 200 patients suffering rCDI with FMT treatment have been reported, resulting in a success rate of $96 \%$ [26]. This is proven by studies such as that of [27]. where patients with at least 2 rCDI episodes received enema administered FMT, with an overall efficacy of $87.1 \%$ and no adverse events related to the treatment. In fact, results are so promising that practice guidelines such as those from the American College of Gastroenterology [28] and the European Society of Clinical Microbiology and Infectious Diseases [29] have already included FMT as a recommended treatment for rCDI.

\section{Conclusion}

In conclusion, $\mathrm{CDI}$ continues to be a serious threat to the public health, especially in hospital environments. The increasing appearance of recurring CDI after conventional treatments such as vancomycin or metronidazole has opened the path for novel treatments. Of these treatments, the fecal microbiota transplant appears to be the most promising, judging by the results of its early applications. Further research is necessary in order to develop optimal administration routes and treatment protocols. 


\section{References}

1 Centers for Disease Control \& Prevention. Antibiotic Resistance Threats in the United States (2013) US. Department of Health and Human Services. 2013.

2 Freeman J, Bauer MP, Baines SD, Corver J, Fawley WN, et al. (2010). The changing epidemiology of Clostridium difficile infections. Clin Microbiol Rev 23: 529-549.

3 Ghantoji SS, Sail K Lairson, DR DuPont, HL Garey KW (2010) Economic healthcare costs of Clostridium difficile infection: a systematic review. J Hosp Infect 74: 309-318.

4 Lessa FC, Gould CV, McDonald LC (2012) Current status of Clostridium difficile infection epidemiology. Clin Infect Dis 55: S65-70.

5 Rupnik M, Wilcox MH, Gerding DN (2009) Clostridium difficile infection: new developments in epidemiology and pathogenesis. Rev Microbiol 7: 526-36.

6 Barbut FJ (2015) How to eradicate Clostridium difficile from the environment. J Hosp Infect. 89: 287-295.

7 Barbut F, Petit JC (2001) Epidemiology of Clostridium difficileassociated infections. Clin Microbiol Infect 7: 405-410.

8 Savage AM, Alford RH (1983) Nosocomial spread of Clostridium difficile. Infect Control 4: 31-33.

9 Walker AS, Eyre DW, Wyllie DH, Dingle KE, Harding RM, et al. (2012) Characterisation of Clostridium difficile hospital ward-based transmission using extensive epidemiological data and molecular typing. PLoS Med 9: e172.

10 Brown WR (2014) Fecal microbiota transplantation in treating Clostridium difficile infection. J Dig Dis, 15: 405-408.

11 McFarland LV, Surawicz CM, Rubin M, Fekety R, Elmer GW, et al. (1999) Recurrent Clostridium difficile disease: epidemiology and clinical characteristics. Infection control and hospital epidemiology. Hosp Epidemiol Am 20: 43-50.

12 Schenck LP, Beck PL, MacDonald J A (2015) Gastrointestinal dysbiosis and the use of fecal microbial transplantation in Clostridium difficile infection. World Gastrointest Pathophysiol 6: 169-180.

13 Shim JK, Johnson S, Samore MH, Bliss DZ, Gerding DN, et al. (1998) Primary symptomless colonisation by Clostridium difficile and decreased risk of subsequent diarrhea. Lancet 351: 633-636.

14 Riggs MM, Sethi AK, Zabarsky TF, Eckstein EC, Jump RL, et al. (2007) Asymptomatic carriers are a potential source for transmission of epidemic and nonepidemic Clostridium difficile strains among longterm care facility residents. Clin Infect Dis 45: 992-998.

15 Cohen SH, Gerding DN, Johnson S, Kelly CP, Loo VG, et al. (2010) Clinical practice guidelines for Clostridium difficile infection in adults:
2010 update by the society for healthcare epidemiology of America (SHEA) and the infectious diseases society of America (IDSA). Infect Control Hosp Epidemiol 31: 431-455.

16 Sheitoyan-Pesant C, Abou Chakra CN, Pepin J, Marcil-Héguy A, Nault V, et al. (2015) Clinical and Healthcare Burden of Multiple Recurrences of Clostridium difficile Infection. Clin Infect Dis.

17 Bakken JS, Borody T, Brandt LJ, Brill JV, Demarco DC, et al. (2011) Treating Clostridium difficile Infection with Fecal Microbiota Transplantation. Clin Gastroenterol Hepatol 9: 1044-1049.

18 Zar FA, Bakkanagari SR, Moorthi KM, Davis MB (2007) A comparison of vancomycin and metronidazole for the treatment of Clostridium difficile-associated diarrhea stratified by disease severity, Clin Infect Di. 45: 302-307.

19 Lancaster JW, Matthews SJ (2012) Fidaxomixin: the newest addition to the armamentarium against Clostridium difficile infections Clin Ther 34: 1-13.

20 McFarland LV, Surawicz CM, Greenberg RN, Fekety R, Elmer GW, et al. (1994) A randomized placebo-controlled trial of Saccharomyces boulardii in combination with standard antibiotics for Clostridium difficile disease. JAMA 271: 1913-1918.

21 The Fecal Transplant Foundation. What is FMT? 2015.

22 Borody TJ, Khoruts A (2012) Fecal microbiota transplantation and emerging applications, Nature Rev Gastroenterol Hepatol 9: 88-96.

23 Eiseman B, Silen W, Bascom GS, Kauvar AJ (1958) Fecal enema as an adjunct in the treatment of pseudomembranous enterocolitis Surgery 44: 854-859.

24 Schwan A, Sjölin S, Trottestam U, Aronsson B (1983) Relapsing clostridium difficile enterocolitis cured by rectal infusion of homologous faeces. Lancet 2: 845.

25 Van Nood E, Vrieze A, Neiuwdorp M, Fuentes S, Zoetendal EG, et al. (2013) Duodenal infusion of donor feces for recurrent Clostridium difficile. N Engl J Med 368: 407-415.

26 Bakken JS (2009) Fecal bacteriotherapy for recurrent Clostridium difficile infection. Anaerobe 15: 285-289.

27 Ornstein R, Dubberke E, Hardi R, Ray A, Mullane K, et al. (2015) Safety and Durability of RBX2660 (microbiota suspension) for Recurrent Clostridium difficile Infection: Results of the PUNCH CD study. Clin Infect Dis.

28 Surawicz CM, Brandt LJ, Binion DG, Ananthakrishnan AN, Curry SR, et al. (2013) Guidelines for diagnosis treatment and prevention of Clostridium difficile infections. Am J Gastroenterol 108: 478-498.

29 Debast SB, Bauer M, Kuiper EJ (2014) ESC MID - updated guideline. Clin Microbiol Infect. 20: 1-26. 